\title{
BMJ Open What do children, parents and staff think about a healthy lifestyles intervention delivered in primary schools? a qualitative study
}

\author{
Joanna Goldthorpe (D) , ${ }^{1}$ Tracy Epton, ${ }^{1}$ Chris Keyworth (D) , ${ }^{1}$ Rachel Calam, ${ }^{2}$ \\ Joanna Brooks (D) ,2 Chris Armitage ${ }^{1,2}$
}

To cite: Goldthorpe J, Epton T, Keyworth C, et al. What do children, parents and staff think about a healthy lifestyles intervention delivered in primary schools? a qualitative study. BMJ Open 2020;10:e038625. doi:10.1136/ bmjopen-2020-038625

- Prepublication history and additional material for this paper are available online. To view these files, please visit the journal online (http://dx.doi. org/10.1136/bmjopen-2020038625).

Received 17 March 2020 Revised 05 June 2020 Accepted 15 June 2020

Check for updates

(C) Author(s) (or their employer(s)) 2020. Re-use permitted under CC BY-NC. No commercial re-use. See rights and permissions. Published by BMJ.

${ }^{1}$ Manchester Center for Health Psychology, University of Manchester, Manchester, UK ${ }^{2}$ Division of Psychology and Mental Health, University of Manchester, Manchester, UK

Correspondence to Dr Joanna Goldthorpe; joanna.goldthorpe@manchester. ac.uk

\section{ABSTRACT}

Objective Primary schools are crucial settings for early weight management interventions but effects on children's weight are small and evidence shows that deficiencies in intervention implementation may be responsible. Very little is known about the roles of multiple stakeholders in the process of implementation. We used a multiplestakeholder qualitative research approach to explore the implementation of an intervention developed to improve the diet and increase the levels of physical activity for children living in some of the most deprived areas of England.

Design For this qualitative study, interviews and focus groups were carried out using semi-structured topic guides. Data were analysed thematically.

Setting Seven primary schools (pupils aged 4 to 11 ) in Manchester, England.

Participants We conducted 14 focus groups with children aged 5 to 10 years and interviews with 19 staff members and 17 parents.

Intervention Manchester Healthy Schools (MHS) is a multicomponent intervention, developed to improve diet and physical activity in schools with the aim of reducing and preventing childhood obesity.

Results Three themes were developed from the data: common understandings of health and health behaviours; congruence and consistency of messages; negotiations of responsibility.

Conclusion All participant groups had a common conceptualisation of health as having physical and psychological components and that action could be taken in childhood to change behaviours that protect long-term health. When parents and staff felt a shared sense of responsibility for children's health and levels of congruence between home and school norms around diet and physical activity were high, parents and children were more likely to accept the policies implemented as part of MHS. Effective two-way communication between home and school is therefore vital for successful implementation of this intervention.

\section{BACKGROUND}

Schools are potentially crucial settings for childhood health promotion interventions, including weight management, ${ }^{1}$ but effect
Strengths and limitations of this study

- This is one of a handful of studies that seeks the views of parents, teachers and children on schoolbased intervention designed to improve children's health and to include the views of all participant groups in the same analysis.

- Weight management and other health promotion interventions delivered in primary and elementary schools have small to null effect on children's weight and adiposity outcomes and that these results may be affected by implementation issues.

- Our findings contribute to a wider literature around the challenges of implementing interventions designed to improve children's health and offers insights into possible reasons why such interventions do not produce meaningful effects on biometric outcomes.

- The views expressed by participants may not be representative, but rather embody the opinions of a group of participants that are more actively engaged with school issues.

sizes for reducing body mass scores (body mass index (BMI), BMI z-score and adiposity) in children are small $(d<0.20)$ and shortterm $^{2}$ or such interventions have been found to be ineffective. ${ }^{3}$ A systematic review of over 500 studies $^{45}$ showed that poor implementation often undermines the effectiveness of weight management programmes meaning that identifying principles of 'successful' versus 'unsuccessful' implementation is vital. Despite this, evaluations of school-based interventions tend to focus on biometric outcomes and neglect wider implementation issues that may affect delivery and outcome of the interventions, such as the local environment, resources available and the degree to which parents and staff support the interventions. ${ }^{6}$ Some evaluation studies of childhood weight management interventions in school settings have involved parents and children 
or staff only. ${ }^{78}$ Others have carried out questionnairebased evaluations. ${ }^{9}$ However ostensibly only one other study ${ }^{10}$ has sought, combined and compared the views of all stakeholders, including parents, pupils and a range of school staff about implementation of childhood weight management interventions delivered in school settings. This means that findings from existing research reflect the views and priorities of specific stakeholders and cannot examine shared values or areas of contention or conflict across all stakeholder groups.

The National Healthy Schools Programme (NHSP) was a national government programme in the UK launched in 1999 by the departments of Health and of Education. The programme's strategic aims were to: support children and young people in developing healthy behaviours; help raise pupil achievement; help reduce health inequalities; and help promote social inclusion. ${ }^{11}$ The programme promoted the links between good health, behaviour and achievement through four key areas: weight management through healthy eating \& physical activity (Healthy Lifestyles) and personal, social and health education and emotional health and well-being (Healthy Minds). ${ }^{12}$ Schools achieved National Healthy School Status if they met key criteria across these four key themes. Although national government funding for NHSP was withdrawn in 2011 as part of a broader set of cuts to health, social care and education funding, a NHSP website containing a toolkit with planning and evaluation guidance was archived and remains available for schools wishing to implement the initiative. ${ }^{13}$ In some areas of the UK (such as Manchester), local health, social care and education services have continued to support NHSP. Weight management is a particular problem in Manchester as $11.4 \%$ of children aged 4 to 5 years and $25.1 \%$ of children aged 10 to 11 years are classified as obese $(B M I>25) ;{ }^{14}$ hence, as part of a sustained public health strategy, there has been continued support post-2011 for the NHSP in Primary Schools (pupils aged 4 to 11) across the city through the Manchester Healthy Schools Team.

In the current qualitative study, we explored the views of a broad range of stakeholders involved in the implementation of the Healthy Lifestyles (ie, weight management) aspect of the Healthy Schools Programme across a range of school settings in one city area. Our aims were to better understand potential facilitators and barriers to implementation from multiple stakeholder perspectives.

\section{METHODS}

The COREQ (Consolidated criteria for Reporting Qualitative research) checklist ${ }^{15}$ informed the reporting of this qualitative study.

\section{Theoretical position}

Our study objectives were deliberately broad and exploratory. We sought to elicit the views of a range of stakeholders (children, parents, staff) involved across a number of schools in the implementation of interventions designed to address the healthy lifestyles (eating and physical activity) themes of NHSP. As such, the approach taken was inductive: we did not impose a fixed theoretical framework on data collection or analysis.

Philosophically, we would identify this research with a 'limited realist' position. ${ }^{16}{ }^{17}$ Qualitative research undertaken from this position assumes a common (shared) reality, but does not seek to view or represent this reality in a neutral and objective way (subjectivities are recognised as an integral part of the research). The aim in limited realist research is to build plausible and credible interpretations rather than to definitively test hypotheses. ${ }^{18}$

\section{Study setting}

Manchester is a major city in the northwest of England with a population of over 530000 . A quarter of the population live in areas ranked as the fifth most deprived in England. ${ }^{19}$ According to Public Health England, children in Manchester have worse than average levels of health and well-being than children in the rest of England. For example, $11.4 \%$ of children aged 4 to 5 years and $25.1 \%$ of children aged 10 to 11 years are classified as obese. ${ }^{1420}$ As part of a sustained public health strategy, there has been continued support post-2011 for the NHSP in Primary Schools (pupils aged 4 to 11) across the city through the Manchester Healthy Schools Team. The Healthy Schools Team advocate a whole schools approach and provide a range of resources and help for schools implementing NHSP via 'Manchester Healthy Schools' (MHS). ${ }^{21}$ Support is provided across five key themes: healthy lifestyles (healthy eating and physical activity), relationship and sex education, mental health, emotional health and drugs and alcohol. This study focusses on the 'Healthy Lifestyles' theme. This citywide support is delivered via a combination of assessment, one-to-one training and resources accessible from a website. ${ }^{22}$ There is no prescribed way of delivering the MHS programme and schools are free to introduce their own policies and strategies based on the standard training and resources.

\section{Sampling and school site recruitment}

We approached 10 schools in total by email and received positive responses from 7. Maximum variation sampling was used to identify mixed sex, state-funded schools participating in the MHS initiative at various stages of implementation and serving a variety of geographical catchment areas in the North, South, East and West of the city. Schools were identified with the assistance of the MHS team to be representative of the ethnic and social demographic make-up of the city's population.

Table 1 shows the IMD score for each school recruited in order of rank (most deprived to least deprived) and their geographical location in the city of Manchester. Seven schools were recruited in total between July 2017 and April 2018 (table 2). The column to the far right of the table indicates that all schools were based in areas representing $10 \%$ (three schools), $20 \%$ (three schools) or $40 \%$ (one school) of the most deprived neighbourhoods 
Table 1 Schools in ranked order of Indices of Multiple Deprivation (IMD) score

\begin{tabular}{llll}
\hline & $\begin{array}{l}\text { Location } \\
\text { within the } \\
\text { city of } \\
\text { Manchester }\end{array}$ & $\begin{array}{l}\text { IMD score } \\
\text { (1 to 32 844 } \\
\text { where one } \\
\text { is most } \\
\text { deprived) }\end{array}$ & $\begin{array}{l}\text { Comparative } \\
\text { \%ch of } \\
\text { deprivation }\end{array}$ \\
\hline $\begin{array}{l}\text { Enterprise } \\
\text { School }\end{array}$ & North East & 936 & $10 \%$ \\
\hline $\begin{array}{l}\text { Priory School } \\
\text { Manor School }\end{array}$ & East & 1110 & $10 \%$ \\
\hline $\begin{array}{l}\text { Park School } \\
\text { City School }\end{array}$ & South West & 1730 & $10 \%$ \\
\hline New School & North & 3524 & $20 \%$ \\
\hline Victoria School & West & 10139 & $20 \%$ \\
\hline
\end{tabular}

*School names are shown as pseudonyms.

in England (based on Index of Multiple Deprivation (IMD) scores for school postcodes obtained from a UK government website. ${ }^{19}$ The IMD ranks every small area in England from 1 (most deprived area) to 32844 (least deprived area). In addition, of 326 local authorities in England, Manchester is the fifth most deprived.

Table 2 shows the characteristics of individual schools recruited into the study as reported on the website for the UK Office for Standards in Education, Children's Services and Skills (OFSTED) https://www.gov.uk/government/ organisations/ofsted. (OFSTED). School ratings are based around four key standards: (1) Effectiveness of leadership and management; (2) Quality of teaching, learning and assessment; (3) Personal development, behaviour and welfare; and (4) Outcomes for children and learners. These standards are assessed by teams of inspectors to create grades: grade $1=$ outstanding; grade 2=good; $3=$ requires improvement; 4=inadequate.)

\section{Participant recruitment}

Study participants were children attending the schools, parents of children attending the schools and members of school staff. Children were interviewed with their peers in focus group interviews; parents and staff took part in one-to-one interviews with a researcher.

\section{Children}

To recruit children, an introductory letter and participant information sheet were circulated to parents of all children in the school by school staff via usual school information sharing networks (shown on the school website, sent home with children in school bags, through text messaging systems). As the likelihood of a child being selected for a focus group is low, and risk associated with participation is low, an 'opt out' approach to participation and informed consent was adopted. ${ }^{23}$ Parents were asked to indicate if they did not consent for their child to be selected for a focus group. If a parent indicated that they did not wish their child to participate, that child was excluded from the study. We ensured that at least 14 days had passed between asking for parental opt out consent and focus group selection to allow for family circumstances such as illness.

Teachers were asked to choose children from each class from within the primary school to take part in a focus group interview based on the following criteria:

Table 2 Characteristics of schools

\begin{tabular}{|c|c|c|c|c|}
\hline School & $\begin{array}{l}\text { Pupils from an ethnic } \\
\text { minority background }\end{array}$ & $\begin{array}{l}\text { Pupils with English as } \\
\text { a second language }\end{array}$ & $\begin{array}{l}\text { Pupils eligible for free } \\
\text { school meals/pupil } \\
\text { premium }\end{array}$ & OFSTED school rating \\
\hline Victoria School & $\begin{array}{l}\text { Most pupils from } \\
\text { an ethnic minority } \\
\text { background }\end{array}$ & Three-fourth of pupils & Around national average & Outstanding \\
\hline Priory School & $\begin{array}{l}\text { Higher than national } \\
\text { average }\end{array}$ & $\begin{array}{l}\text { Higher than national } \\
\text { average }\end{array}$ & $\begin{array}{l}\text { Higher than national } \\
\text { average }\end{array}$ & Good \\
\hline Enterprise school & $\begin{array}{l}\text { Higher than national } \\
\text { average }\end{array}$ & $\begin{array}{l}\text { Higher than national } \\
\text { average }\end{array}$ & Above national average & Good \\
\hline Park School & Above average & Above average & $\begin{array}{l}\text { Twice the national } \\
\text { average }\end{array}$ & Good \\
\hline Manor School & $\begin{array}{l}\text { Most pupils are White } \\
\text { British }\end{array}$ & $\begin{array}{l}\text { Lower than average } \\
\text { with increasing } \\
\text { numbers }\end{array}$ & $\begin{array}{l}\text { More than twice the } \\
\text { national average }\end{array}$ & Good \\
\hline City School & $\begin{array}{l}\text { Almost all pupils from } \\
\text { Pakistani or Bangladeshi } \\
\text { heritage background }\end{array}$ & Most pupils & Average & $\begin{array}{l}\text { Requires improvement } \\
\text { (previously outstanding) }\end{array}$ \\
\hline New School & $\begin{array}{l}\text { Well above national } \\
\text { average }\end{array}$ & $\begin{array}{l}\text { Well above national } \\
\text { average }\end{array}$ & Above national average & Good \\
\hline
\end{tabular}

OFSTED, UK Office for Standards in Education, Children's Services and Skills. 
(a) considered able to engage in and contribute to a 45 min focus group and (b) considered able (and given the opportunity) to catch up with any work missed during their absence from class. We also asked teachers to recruit a mix of male and female pupils and a mix of pupils having school dinners and bringing packed lunches (in order to gain a balanced perspective relating to parental versus school responsibility for lunches). Class teachers further gave information to the children selected for focus groups using simple text and pictures and children were given the opportunity to ask questions about the study and focus groups. The children were told before the focus groups began that they could leave at any time.

\section{Parents/carers}

We aimed to recruit two parents/carers per school. An introductory letter and participant information sheet was circulated by school staff via usual school information sharing networks as above. Parents and carers interested in participating could contact the research team through a closed study Facebook group, by emailing the lead researcher or by returning a reply slip included with the information sheet to the school. Potential participants were then contacted by the research team directly to make arrangements for their interview.

\section{Staff}

We aimed to recruit five staff members from each schools (ones each with the following roles: head teacher; healthy schools coordinator; school governor; school cook; lunchtime assistant; teacher from key stage 1; teacher from key stage 2). Potential staff participants were identified at an initial introduction meeting with the head teacher or healthy schools coordinator at each school, who informed relevant staff about the research project and circulated participant information sheets. Staff interested in participating could contact the research team directly or via the head teacher or healthy schools coordinator. Potential participants were then contacted by the research team to make arrangements for their interview.

Seventeen parents (11 female and 6 male) and 19 staff members (15 female and 4 male) were recruited (please see online supplementary file 1 for more detailed reporting of characteristics). Of the staff participants, six were head teachers, five were healthy school coordinators (staff member appointed lead for implementing MHS;,typically deputy head teachers or pastoral care lead), four were key stage 1 teachers, five were key stage 2 teachers, five were school cooks, four were lunchtime organisers and two were school governors (in England the role of school governor is held by a person who is not employed by the school and is drawn from the wider school community. For example, a school governor might be a parent, a member of the community or a local organisation's representative). Of the total participants, 19 were female. Of the parent's sample, three parents also had professional or strategic connections to the schools involved in the study: one parent also had a parent/governor role, one parent worked as a teaching assistant and one worked as a school cook.

\section{Data collection}

Topic guides were semi-structured and based on a review of relevant literature and structured according to Normalisation Process Theory, ${ }^{24} 25$ an established theory of implementation that is based around four constructs (Coherence, Cognitive Participation, Collective Action and Reflexive Monitoring).

\section{Focus groups with children}

Focus groups were based on the principle of participating in 'research with' rather than 'research on' the child. ${ }^{26}$ One hundred and thirty-three children from (England and Wales) national curriculum key stages 1 (ages 4 to 8 ) and 2 (ages 8 to 11) participated in separate groups. This was because we wanted to capture a shared experience based on the degree of autonomy with regard to choices that may differ between older and younger children. An equal number of boys and girls took part in the focus groups. A topic guide explored implementation of the MHS programme using semi-structured questions organised around a review of current relevant literature. The focus groups took place in a quiet room on the school premises and were facilitated by two experienced members of the research team. Facilitator 1 (JG) asked the children questions from the topic guide and in response to issues and topics raised by the children. Facilitator 2 (CK or TE) audio-recorded the interviews, checked for signs of discomfort or distress among participants and responded to issues and topics raised directly by the children. The mean length of time for focus groups involving children from key stage 1 was 37 min (range 25 to $53 \mathrm{~min}$ ) and for children from key stage 2 the mean length of the focus groups was $40 \mathrm{~min}$ (range 27 to 54). More details relating to individual schools and the children who participated in the focus groups can be found in online supplementary file 2 .

\section{Interviews - parents/carers and staff}

All participants were given the choice of participating in interviews either face-to-face in a quiet room in the school or over the telephone. Two parents and three staff chose to have their interviews take place over the telephone, with the remaining participants choosing to be interviewed on school premises. Interviews were audiorecorded and transcribed verbatim. Informed consent was taken prior to interviews commencing.

An experienced qualitative researcher with a background in psychology and research with children and families (JG) conducted all of the interviews, which lasted between 15 to $52 \mathrm{~min}$ for parents and between 17 to $66 \mathrm{~min}$ for staff (mean length 36.41). Interviews were semi-structured and based around a topic guide, allowing for flexibility to pursue topics of interest should they arise. The topic guides explored implementation of the MHS programme using semi-structured questions 
organised around a review of current relevant literature. Participants were aware of the role and background of the researcher.

\section{Analysis}

Thematic analysis was used as an appropriate approach for analysis, in keeping with the inductive exploratory aims of the study. We drew on the guidance to thematic analysis presented by Braun and Clarke (2006) ${ }^{27}$ Given the size of our data set, initial coding was pragmatically undertaken in parallel with completion of interviews. Data were at first organised according to participant groups (staff, parents and children) and coding (assigning descriptive labels to relevant material) undertaken on each data set. Analysis (coding and initial development of themes) was undertaken by the first author and research team discussions held at regular intervals to discuss, refine and elaborate codes and to group these into developing themes. Discussion within the research team and subsequent refinement of codes and themes established trustworthiness in the findings of the analysis. ${ }^{28}$ NVivo 11 (QSR international) software was used to organise data. As descriptive codes developed from across the three data sets were similar, these were then synthesised and further developed into overarching analytical themes. A thematic structure was developed and applied to the data set to ensure it well represented and was consistently evidenced by the data. After reviewing the data, the authors felt confident that the data obtained was rich and insightful enough to satisfy the aims of the study and that the sample size was appropriate. $^{29}$

\section{Patient and public involvement}

Members of the public, including parents, teachers and children reviewed our research materials (participant information, consent forms and topic guides) prior to use. Appropriate revisions were made basedon their valuable input.

\section{RESULTS}

Thematic analysis of the data set focussed on the identification of patterns across participant accounts. Three overarching themes and subthemes developed through analysis are presented here: Common understanding of health and health behaviours (biopsychosocial and holistic model, prevention and protection); Congruence and consistency of messages (setting a good example and role modelling; macro environment and social norms); and Negotiation of responsibility (societal responsibility, school responsibility and parental responsibility). These themes (in bold headings) will be described in more detail and organised according to subthemes (subheading in italic). Representative quotes provided from individual participants are presented to evidence patterned responses across the data set. Quotations will be provided (in italics) to illustrate and provide evidence for the findings and the source of evidence will be shown in brackets after the quotations.

\section{Common understandings of health and health behaviours}

This theme relates to understandings of what it means to be healthy, and how the aims of the MHS programme fit with this understanding. These understandings were similar across participant groups.

\section{Biopsychosocial and holistic model}

All participants articulated a holistic biopsychosocial model of health that encompassed understanding of a relationship between lifestyle-related factors such as diet and physical activity, the resulting effects on the body and subsequent feelings and behaviours. All participant groups linked eating a healthy diet and engaging in physical activity with benefits for both mental and physical health. Learning about the effects of food and physical activity on health was often incorporated into the teaching curriculum, which may have promoted a shared understanding between staff and children. School staff sought to develop broad comprehension of health and a shared definition of what it means to be healthy within the school community:

I'm very much mindful...that telling a child that a banana is good for you but a packet of sweets is notwhat does that mean and what does that mean to that child? So I actually explain to them what that banana does to your body and how that affects your body and what different foods mean to your body and why the chocolate isn't as good for you

(Staff (Healthy Schools coordinator), Victoria School)

\section{Prevention and protection}

Participants were particularly mindful of the potentially negative effects of some foods on health and behaviour, and all participant groups highlighted sugar in particular as influencing children's behaviour. Staff and parents described children becoming 'hyperactive' and demonstrating challenging behaviour following the consumption of sweets and sugary drinks. Children themselves described the effects of sugar on their bodies similarly:

'Hyper' means that if you eat too much sugar, so if you eat two bags of sweets, then because of the sugar, eating too much sugar, you start to get hyper and you start getting out of control as the sugar acts on your body.

\section{(Key stage 2 focus group, Park School)}

Physical activity was viewed as having a contrastingly positive effect on behaviour. Some staff members used structured physical activity as part of a strategy for managing challenging behaviour. Adult participants felt that initiatives such as the daily mile (an initiative to get all children in the UK completing one mile walking or 
running during each school day) generally improved pupils' behaviour:

I think there are some children with behaviour issues ... So I think that bit of exercise helps get that the release, get that energy out especially when they have been sat for a long time.

(Parent/carer, Manor School)

Children also reported experiencing a connection between physical activity, feelings and emotions and subsequent behaviour. The quote below illustrates this child's understanding of the link between engaging in physical activity, how it helped him manage his emotions and the subsequent effect on his school work:

Child: When I was running it got everything out of my mind.

Interviewer: That's really interesting.

Child: I think I did my work faster than I could run. Like all the things that had been upsetting me...Yeah, you just run. And when you're running it just goes out.

(Key stage 2 focus group, Enterprise School)

Staff and parents felt that being physically active could additionally build self-confidence in children through achievement following managed risk taking, such as being encouraged to climb higher on a climbing frame or braving the cold weather to play outside. Both staff and parents associated having the confidence to engage in physical activity, particularly outdoors, with better overall fitness and improved physical health in children. Schools were understood as an appropriate environment in which this confidence building could take place and schools often provided opportunities for such learning.

[Forest School, an outdoor learning space] promotes that love of outdoor learning, children just being outside. Taking more risks, when we initially started doing Forest School we would have a lot of children who were crying, 'I'm cold, I'm this, I don't want to do it', whereas, now they can't wait to get down there. So, they need to be well wrapped up when it's cold, they need a sun hat when it's warm, so they're becoming more responsible for their needs.

(Staff (Healthy Schools coordinator), Enterprise School)

All participant groups understood establishing such preferences and habits in early life as a means of preventing illness in adulthood, and many of the strategies implemented as part of MHS were seen as offering children protection against disease and ill health in later life.

I think if you get them when they're young, they follow it through life, don't they? I think sometimes that, kind of, idea of prevention is better than cure.

(Staff (Healthy Schools coordinator), New School)
The focus of children themselves was (understandably) on protection and prevention in the shorter-term and was primarily related to dental health. Children cited preventative behaviours such as reducing sugar intake through consuming fewer sweets and fizzy drinks. Many children reported experience of tooth extraction or knew another child who had teeth removed and protective health behaviours were mentioned mainly in the context of oral health and tooth brushing.

My dad always gets me healthy food, and he always reminds to clean my teeth because if you don't clean your teeth then the food won't come off and your teeth won't stay healthy. (Key stage 2 focus group, City School)

\section{Congruence and consistency of messages}

The extent to which MHS policies and messages were congruent with what children observed others doing, including perceived norms both inside and outside school, were important potential facilitators or barriers to implementation.

\section{Setting a good example and role modelling}

Teachers and children reported that the behaviour of other adults and peers was important in establishing normative behaviour. Teachers described eating food items banned from school out of the view of children and ensuring they were only seen drinking water in the classroom in order to model the behaviour they expected from the children. Teachers with active lifestyles, such as those who were successful in competitive sport, were seen as good role models for pupils:

And [teacher], so he's a real aspiring footballer. $\mathrm{He}$ plays for [name of club] so I think he's just, like, it's amazing ...I think it does encourage them to be active more, not just about football.

(Staff (Healthy Schools coordinator), New School)

Children expected teachers to be good role models and acceptability of MHS policies could be undermined when teachers did not act in accordance with school rules or expected behaviours:

Child 1: In school, it's a healthy school but some of the teachers are eating unhealthy food. A few days ago, I saw two of the teachers; they were giving crisps to each other. And I don't think that's fair on us.

Child 2: Yeah, it's hypocrisy, isn't it?

(Key stage 2 focus group, Victoria School)

\section{Macro environment and social norms}

The extent to which MHS messages provided in the school environment were congruent with norms outside of school was an important potential facilitator or barrier to implementation. Marketing and advertising were described by participants as problematic in a number of ways. Sales tactics ('buy one, get one free', free gifts, 
strategic placing of unhealthy foods in shops) were seen as encouraging the consumption of fatty and sugary foods, particularly among children.

Child 3: I think it's also the supermarkets as well because they always try to draw you in with fast foods. $\mathrm{Oh}$, get this for half price. If you buy one, get one free.

Child 4: It's also the supermarkets that...and also... because they try to draw you in to trying to get oh, for example, let's say, [fast food outlet] say, 'buy one [dessert], get the other [dessert] half price'. They're going to ban those adverts.

\section{(Key stage 2 focus group, Victoria School)}

All participant groups additionally reflected on ambiguities in marketing, and how some food items (eg, tomato ketchup, cereal bars, packaged dried fruit snacks, yoghurts) marketed as being healthy (eg, containing fruit, vegetables or vitamins) are actually high in sugar or salt content. The realisation that these items were not as healthy as first thought often came after they had become established part of families' diets.

I think that's what the downfall is at the moment because you think that things are healthy but everything seems to have a lot of sugar in it. I've had yoghurts for a long time, 'Oh, yeah, I'm having a yoghurt, it's really good for me' and it's, like, 'Oh, no, it's not'... you fill children with yoghurts, it's good for them. And it was, like, 'They're really not'. And then you literally have to get natural yoghurt, cut up some fruit and mix it, and if you don't give that to start with and you give [name of yoghurt] then they're not going to want [plain yoghurt with fruit] later!

\section{(Parent/carer, City School)}

Adult participants (parents and staff) saw cultural background and habitual patterns of eating and activity within families as a potential barrier to implementation of MHS messages when incongruence between home and school was high. Examples given included: visiting fast food restaurants regularly or on a certain day of the week; to always have a packet of crisps with a sandwich and to use the car instead of walking short distances. Participants acknowledged that changing established patterns could be difficult.

As an adult you get your natural supermarket pattern, don't you, where you go to the supermarket, and you tend to put the same things in your basket, every week, don't you? And I suppose, if you've always been that, I have my pie and chips, and my fish and chips, 'cause I've had conversations with parents about balanced diets, and they've talked about going to various different takeaways on each nights

\section{(Staff (head teacher), Priory School)}

Participants felt that norms established in families were also pertinent to the ways in which children engaged with physical activity at school. If children engaged in mostly sedentary activities at home (going straight home to watch a television programme or play a computer game), they could be nervous and avoidant regarding physical activity.

Most of them would probably rather sit at home and instead of coming to an afterschool club they'd rather be on their X-box or PlayStation at home. I think that's a big one. The parents as well, the parents' support in getting them involved in things. I know that some of our children haven't participated in PE yet because they've not got the kit, and things like that.

\section{(Key stage 2 teacher, Monastery School)}

Teachers at Victoria and City schools highlighted that swimming lessons could be particularly fraught for children who had never been swimming or worn a swimming costume before and cited children frequently trying to avoid swimming lessons by not bringing their towels and costumes to school. The following parent described how children from her local Muslim community could find it difficult to combine after school sporting activities with cultural and religious norms, such as attending the local Mosque in the evenings.

There's very little time, especially when it's dark at 3 o'clock. You want to go home. And our Asian community has a mosque. So our children are doing a lot from 5 to 8 , so they're very stressed. So that's why I'm saying they hardly get time for anything. In this community, if you think about them, like 90 to 95 per cent are Muslim ... I would say 90 per cent of the children go to mosque, which is 5 p.m. to 8 p.m.

(Parent/carer, City School)

However, adult participants also discussed how concordance between established habits at home and at school could facilitate implementation of MHS. Additionally, parents and staff felt that children's exposure to MHS could positively influence decisions made at home relating to diet and activity, challenging established norms. Parents could also feel more supported in their own efforts to promote health behaviours-for example, those who monitored the amount of sugar, fat and salt their child was eating could feel supported by school's healthy lunchbox policies and less pressured into including unhealthy food in their packed lunch.

He will say, 'Mummy I want a packed lunch', I will say, 'there is no different with what I will give you with what you are given in school'....I will just put some water there, I'll put apple there and say, 'Take your packed lunch' ... I think maybe some children think, 'I'm going to get my mummy to put all the treats in there' ... So I think it works together from home and school

(Parent/carer, Priory School) 


\section{Negotiations of responsibility}

The final theme describes who it was participants understood as having responsibility for children's health and health behaviours, and the extent to which those seen as having responsibility were perceived as able to fulfil this. Parents, staff, children themselves and national government were all understood as having some level of responsibility for children's health.

\section{Societal responsibility}

All participant groups drew attention to broader societal influences on children's health and health behaviours.

It's the Government's job, the Government sort out all the money and stuff. So the school get a certain amount of money, and then the school have to spend it wisely. So they spend it really wisely on getting fruit and vegetables.

\section{(Key stage 2 focus group, Victoria School)}

Some parents felt that national government could meet their responsibility to support children's health by subsidising school meals for older children, in addition to funding school meals for children in key stage 1 (school meals are currently universally free of charge from reception to year 2 in UK primary schools and then meanstested). School dinners were seen as healthier and more convenient than packed lunches but prohibitively costly, particularly for those with more than one child at school.

At the moment because school dinner ... £11.15 [per week, per child] is very expensive. We are really struggling...They are actually providing a healthy lunch, but it's too much. If the whole school became free school dinners, that would actually play two parts in this. Number 1, every single child is eating the same. So we know which level they're growing at, there will be no complaints. So we'll know where this obesity or anything is coming from, because everybody is eating the same. Number 2 is saying, "money for working parents who are struggling'. So I think the Government should take this seriously

(Parent/carer, City School)

\section{School responsibility}

All participant groups accepted that schools have an in loco parentis' role, where schools are responsible, not just for delivering an academic curriculum, but for their pupils' overall physical health and emotional well-being. School staff felt that this nurturing role could extend to offering support for parents and families, particularly those who may have difficulties in providing and caring for their children. However, staff reported tensions between the importance they personally ascribed to promoting children's health and health behaviours and other external pressures faced around delivering the national curriculum and meeting government-set targets for children's academic achievements in a context of austerity-driven cuts to publicly funded services. While valued at a school level, children's physical health and emotional well-being were not perceived as taking similar priority at national government level.

I think we can have quite an impact with the children but I think with the restraints with the curriculum at the moment, there's that many things, that you feel it's just jam-cram-packed. So I think a lot is passed on to schools to sort of try and deal with that, but I don't think we have the resources, I don't think we have enough money; and I think the pressures on schools to get results rather than actually a rounded child sometimes is problematic... It doesn't matter how much emphasis you put on mental health, or well-being, or healthy eating, that they're the things that are still not seen as important as maths, literacy, science. (Staff (head teacher), Manor School)

School staff described themselves as being well aware of children's particular family circumstances, and several gave examples of regular but unspoken instances of needing to 'bend the rules'. For example, children were able to buy snacks from the school tuck shop at discounted rates.

I have this one boy ... He's one of seven children in his family, and every day he'll tell me he's lost his $20 \mathrm{p}$, and every day I'll say, 'Let's go and get a piece of fruit'. I'm not going to say, 'No you haven't lost it, you say it every day, flipping go away'. And his sister's started doing it in year four. She'll look at me and go, 'Miss, I've lost my 20p'. I'll say, 'Right, go and get a piece of fruit'

(Staff member (Healthy Schools coordinator), Priory School)

\section{Parental responsibility}

In this final subtheme, there was greater evidence than elsewhere in the analysis of divergent participant responses and all groups of participants felt that parents were primarily responsible for their children's health. Sometimes participants reported resistance from parents in relinquishing responsibility for their children's dietary intake and this could affect the ability of schools to control children's food during school hours, particularly when parents did not support the healthy eating policies in place.

[Parents] are coming from a place where they think, 'I'm responsible for what my children eat and I don't want other people telling me'

\section{(Parent/carer, Manor School)}

Some parents were openly resistant to changes made by schools regarding rules for food and drinks permitted by schools for children's' packed lunches. Staff could find it difficult to talk to parents about the packed lunch policies in this context.

I had one, a complaint recently, about the fact that this parent feels that she is more than capable of 
deciding what her child can and should eat, and this is not our responsibility to tell her as a parent what her child can and cannot eat. So those sorts of discussions are very difficult.

\section{(Staff (head teacher), Victoria School)}

Some parents additionally felt that changes in rules relating to school food, particularly packed lunches, had resulted in their children becoming overanxious about what was permitted. This was of particular concern when the Healthy Schools programme was in the early stages of implementation.

So, she had that anxiety before [clarification of permitted foods], of what was in her packed lunch. And I have heard of other children having absolute fits about, 'I can't put that in, I can't put that in', because they've been so worried. We need it as a friendly, 'this is good for you, this is what we're doing', kind of thing. It's been, 'these are the rules, that's how it's going to be from now on. You will get told off.'

(P012, Priory School).

All participant groups understood parents as primarily responsible for their children's health and health behaviours. However, participants suggested there could be limits to parents' ability to exercise this responsibility due to lack of money, resources and knowledge.

I don't think they know a lot. I think it's just like, well, my kid likes eating them so that's what they're going to have.

(Staff (head teacher), City School)

It's hard and even if you're working it's still hard because to eat healthy is expensive as well. Sometimes the cheaper option is a better option because you've not got an extra $£ 3$ to spend on the healthier one so you just end up getting the unhealthier one.

\section{(Parent/carer, Enterprise School)}

Participants felt that children were, despite their young age, able to take some responsibility for making choices that affected their own health. Some children associated being overweight with poor health and expressed judgemental and negative views towards people they considered fat.

Child 1: If you're fat, it's your fault. If you're fat, it's your fault you're fat.

Child 2: If you're fat and you want to go shopping, you can't get into the door of the shop, you can't make it. If it opens and you can't fit, you're too fat, yeah, you can't go in.

Child 3: You need to lose some weight.

(Key stage 2 focus group, Priory School)

Some children did give examples of how they had used their newly acquired knowledge to take responsibility for food choices, particularly around adherence to school rules regarding healthy eating. This often involved reminding parents of what food was considered appropriate for packed lunches:

It's your responsibility to recognise if your parents are getting the wrong food, if you don't recognise then you have to remind yourself.

(Key stage 2 focus group, City School)

Children would relay messages delivered at school to their families and make suggestions based on this new knowledge, particularly in relation to food:

It's going in. You can tell it's going in 'cause when kids come home and they start telling you stuff that you can't have because it's got too much fat in and stuff like that.

\section{(Parent, Manor School)}

Parents and staff felt that children were learning to take responsibility for their own health as they got older and welcomed the development of this skill. Some staff members suggested that children could be more open to accepting advice and information than adults and that their new knowledge could, in turn, inform and affect the choices made by other individuals such as peers and family members.

Start with the children first. Don't try and tell the parents how to manage their lives, because they're already set in their routine. You've got young flexible children, who will have a thirst for knowledge. Give them the information, work with them, and get them to either use peer conversations, or whatever, to do it, or actually just instil within them, the importance of that.

(Governor, Park School)

\section{DISCUSSION}

Staff, parents and children shared similar perceptions of health as a holistic, biopsychosocial construct that encompassed physical and mental health and quality of life. Emphasising these shared, holistic concepts of health in teaching and communication around the aims of MHS could therefore act a facilitator to both initial engagement with parents and children and sustained implementation.

Discussions around responsibility and control reflected arguments broadly consistent with political philosophies relating to individualism and collectivism, which reflects an established dichotomy that frames a wider, global debate around who is responsible for health in developed societies. ${ }^{30-32}$ Individuals within all participant groups, including children, expressed variable views around who is responsible for children's health on a spectrum ranging from individuals themselves (individualism) to government and wider society (collectivism). Some children in key stage 2 were able to understand and debate these sophisticated concepts ("it's your fault if you're fat" vs "it's 
the government's fault"); this is explored in greater detail in another paper. ${ }^{33}$ If parents concurred that schools had some responsibility for their children's health, they were more accepting of the MHS food policies. However when MHS policies challenged parent's notions of control over what their children should be permitted to eat, barriers to compliance with school food policies (particularly those relating to food permitted in children's packed lunches) could be raised. This finding has resonance with the work carried out by Clarke et al, ${ }^{34}$ who found that parents who saw a primary school-based healthy lifestyles intervention as a partnership between the home and school expressed more positive views about the intervention. All participant groups recognised that advertising, fast food and sedentary lifestyles negatively impacted on health and consequently, government and societal organisations had a responsibility to restrict their ability to affect children's health. The importance of recognising aspects of social and contextual influence in childhood obesity programmes has been recognised in a recent systematic review. $^{35}$

Participants were amenable to MHS initiatives when they were similar to their own established social norms around diet and physical activity. This includes habitual behaviours developed over time within individuals, families and groups, cultural background and modelling of behaviour by individuals playing significant roles in children's lives. Staff accepted that changing some established habits of pupils and their families can be challenging and act as a barrier to engagement. Families' cultural background could also influence the habits formed by parents and children, such as wider family members habitually consuming food which is high in fat and sugar or a need to attend religious classes after school that restrict participation in after-school activities. However, a number of responses from all participant groups suggested that some of the messages delivered through MHS may be influencing children's' home environment. For example, reinforcing messages about healthy diets and school food rules appeared to be associated with the improved content of packed lunches brought from home that may subsequently be having effect on the shopping and food preparation habits of families. There has been a rise in the number of children bringing packed lunches to school, particularly over the past three decades ${ }^{36}$ and research has shown that school dinners are generally higher in nutritional value than packed lunches. ${ }^{37}$ Policies that affect the content of school packed lunches therefore have potential to have an impact on children's overall nutritional intake, for example. ${ }^{38} 39$

\section{Strengths and limitations}

This is the first qualitative research study to focus on the implementation of a health promotion intervention in UK primary schools involving participants from all relevant stakeholder groups. Our findings support a multi-stakeholder, multi-system approach to child health. Successful implementation and engagement with children, staff, parents and the wider community is vital if MHS is to positively affect health and weight outcomes for children. ${ }^{40}$ This is particularly important given the low effect sizes for weight loss produced by many similar school-based interventions.

An important limitation of this study is that the views expressed by participants may not be representative of a larger sample, but rather embody the opinions of a group that is more articulate and actively engaged with MHS. Children were selected by teachers to participate in focus groups and many (although not all) of the parents involved in the study were recruited via school staff. Therefore findings may not represent all children and parents and results should be interpreted with this in mind.

\section{Implications for future research}

Schools implemented MHS in idiosyncratic and unstandardised ways. For example, every school has a healthy school coordinator, however this is not a protected role. Typically, deputy head teachers or pastoral officers undertake this role voluntarily, in addition to their usual paid tasks. Thus, the capacity of individuals to dedicate time to healthy-schools related tasks and their ability to delegate varies. This presents an obstacle to carrying out research around the effectiveness of the both the policies and initiatives that make up MHS. ${ }^{1041}$ For example, assessing fidelity to the intervention ${ }^{42}$ in a randomised trial of MHS would be extremely challenging. It may be helpful to carry out some case studies within schools to establish which behaviour change techniques ${ }^{43}$ are being used and whether it is possible to quantify the extent and consistency that they are being applied. This may contribute to establishing a framework for evaluating health behaviour change interventions in primary schools. Further, given the difficulties inherent in gathering meaningful data on weight outcomes in children due to natural, developmental fluctuations taking place that affect children's weight/height ratio, particularly around the onset of puberty ${ }^{40}$ a focus on measuring changes in health behaviours in addition to biometric outcomes may provide additional useful and appropriate outcomes for judging the success of childhood healthy lifestyle interventions.

In conclusion, this study suggests that improving communication and understanding between the home and school is vital to successful implementation of interventions designed to improve diet and levels of physical activity. Future research should therefore focus on developing effective ways for schools to reach and engage with parents and carers, and creating an environment that promotes the health and well-being of children should be at the heart of this work. Assumptions of responsibility for children's health and established social norms congruent with the aims of health promotion interventions may need to be negotiated within this context. However, highlighting the shared understanding of children's health as encompassing holistic and preventative aspects may 
offer a promising approach to overcoming barriers to generating a common understanding between home and school in other areas. Establishing an effective communication strategy between home and school is therefore vital for successful implementation. In addition to having implications for the ongoing implementation of MHS, our findings may also have resonance for other health promotion interventions delivered in primary schools, such as mental health support initiatives or weight management interventions aimed at young children in other settings.

\section{Twitter Joanna Goldthorpe @JoannaGoCarroll}

Collaborators Emma Schneider of Central Manchester University Hospitals NHS Foundation Trust supported recruitment of the schools into the study. We would like to thank the staff at the schools involved in this study for giving up their tiime to talk to us, facilitating the focus groups and for their excellent nurturing of debating skills among the pupils, which certainly contributed to the richness of the data we captured. We would also like to thank the parents and children involved for giving up their time to share their views in such an articulate and enlightening way.

Contributors JG conceived and designed the study, collected the data, conducted the analysis and wrote the manuscript. TE assisted with data collection, contributed to the analysis and contributed to the final version of the manuscript. CK assisted with data collection, contributed to the analysis and contributed to the final version of the manuscript. JB contributed her expertise in qualitative research to the data analysis and contributed to the final version of the manuscript. RC obtained the funding, contributed to the study design and analysis and provided critical revision of intellectual content for all versions of the manuscript. CA obtained the funding, contributed to the study design and analysis and provided critical revision of intellectual content for all versions of the manuscript.

Funding The authors have not declared a specific grant for this research from any funding agency in the public, commercial or not-for-profit sectors. This study was funded by a research grant obtained from Tesco PIc and was supported by the NIHR Manchester Biomedical Research Centre and the NIHR Greater Manchester Patient Safety Translational Research Centre. Tesco Plc had no role in the design of this study and did not have any role during its execution, analyses, interpretation and storage of the data or decision to submit results.

Competing interests None declared.

Patient consent for publication Parental/guardian consent obtained.

Ethics approval Ethical approval was given by the University of Manchester Research Ethics Committee, reference 2017-1674-2986.

Provenance and peer review Not commissioned; externally peer reviewed.

Data availability statement Data are available upon reasonable request. We have consent from participants to publish selected quotes only. Selected extracts that provide contextual information for the quotations used are available from the lead author on request; however some data may be removed to protect the anonymity of participants.

Open access This is an open access article distributed in accordance with the Creative Commons Attribution Non Commercial (CC BY-NC 4.0) license, which permits others to distribute, remix, adapt, build upon this work non-commercially, and license their derivative works on different terms, provided the original work is properly cited, appropriate credit is given, any changes made indicated, and the use is non-commercial. See: http://creativecommons.org/licenses/by-nc/4.0/.

\section{ORCID iDs}

Joanna Goldthorpe http://orcid.org/0000-0001-7839-7544

Chris Keyworth http://orcid.org/0000-0002-7815-6174

Joanna Brooks http://orcid.org/0000-0003-0220-9847

\section{REFERENCES}

1 Dudley DA, Cotton WG, Peralta LR. Teaching approaches and strategies that promote healthy eating in primary school children: a systematic review and meta-analysis. Int J Behav Nutr Phys Act 2015;12:28.
2 Oosterhoff M, Joore M, Ferreira I. The effects of school-based lifestyle interventions on body mass index and blood pressure: a multivariate multilevel meta-analysis of randomized controlled trials. Obes Rev 2016;17:1131-53.

3 Adab P, Pallan MJ, Lancashire ER, et al. Effectiveness of a childhood obesity prevention programme delivered through schools, targeting 6 and 7 year olds: cluster randomised controlled trial (WAVES study). BMJ 2018;360:k211.

4 Durlak JA, DuPre EP. Implementation matters: a review of research on the influence of implementation on program outcomes and the factors affecting implementation. Am J Community Psychol 2008;41:327-50.

5 Wolfenden L, Nathan NK, Sutherland R. Strategies for enhancing the implementation of school-based policies or practices targeting risk factors for chronic disease. Vol. 2017, Cochrane database of systematic reviews. John Wiley and Sons Ltd, 2017.

6 McGoey T, Root Z, Bruner MW, et al. Evaluation of physical activity interventions in children via the reach, efficacy/effectiveness, adoption, implementation, and maintenance (RE-AIM) framework: a systematic review of randomized and non-randomized trials. Prev Med 2016;82:8-19.

7 Clarke JL, Griffin TL, Lancashire ER, et al. Parent and child perceptions of school-based obesity prevention in England: a qualitative study, 2015. Available: https://bmcpublichealth. biomedcentral.com/track/pdf/10.1186/s12889-015-2567-7 [Accessed 17 Dec 2018].

8 Rawlins E, Baker G, Maynard M, et al. Perceptions of healthy eating and physical activity in an ethnically diverse sample of young children and their parents: the DEAL prevention of obesity study. $J$ Hum Nutr Diet 2013;26:132-44.

9 Sahota P, Rudolf MC, Dixey R, et al. Evaluation of implementation and effect of primary school based intervention to reduce risk factors for obesity. BMJ 2001;323:1027-9.

10 Griffin TL, Pallan MJ, Clarke JL, et al. Process evaluation design in a cluster randomised controlled childhood obesity prevention trial: the WAVES study. Int J Behav Nutr Phys Act. 2014;11.

11 Arthur S, Barnard M, Day N, et al. Evaluation of the national healthy schools programme final report, 2011. Available: http://www. natcen.ac.uk/media/28170/evaluation-national-healthy-schools.pdf [Accessed 24 Mar 2017].

12 Ogilvie F. National Healthy Schools Programme - The Lancet UK policy matters. Lancet. Available: http://ukpolicymatters.thelancet. com/policy-summary-national-healthy-schools-programme/ [Accessed 24 Mar 2017].

13 Department for Education (National Archives). Healthy schools. Available: http://webarchive.nationalarchives.gov.uk/ 20130123124929/http:/www.education.gov.uk/childrenandyoung people/healthandwellbeing/a0075278/healthy-schools-toolkit

14 Johnson J. Child health profile. Health visit. , 1987: 60, 244-5. www.nationalarchives.gov.uk/doc/open-government-licence/ version/3/

15 Tong A, Sainsbury P, Craig J. Consolidated criteria for reporting qualitative research (COREQ): a 32-item checklist for interviews and focus groups. Int J Qual Health Care 2007;19:349-57.

16 Hammersley M. What's wrong with ethnography? methodological explorations | ALNAP, 1992. Available: https://www.alnap.org/helplibrary/whats-wrong-with-ethnography-methodological-explorations [Accessed 12 Sep 2019].

17 Brooks J, King N. Applied qualitative research in psychology. London: Macmillan, 2018. Available: https://books.google.co.

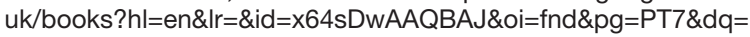
Brooks,+J.+and+King,+N.+(2017).+Approaches+to+qualitative+ psychology.+In+J.Brooks+and+N.King+(Eds),+Applied+qualitative+ research+in+psychology.+Palgrave.\&ots=Guz5ZJAWFe\&sig=pgf1rz [Accessed 12 Sep 2019].

18 King N, Bravington A, Brooks J, et al. "Go make your face known": Collaborative working through the lens of personal relationships. Int $J$ Integr Care 2017; 17:ijic.2574.

19 Department of Communities and Local Government. English indices of deprivation 2015, 2015. Available: https://www.gov.uk/ government/statistics/english-indices-of-deprivation-2015

20 Deplewski D, Rothenburg SS, Kumar S. Obesity in children Symptoms, diagnosis and treatment | BMJ Best Practice, 2019. Available: https://bestpractice.bmj.com/topics/en-gb/1085 [Accessed 3 Jun 2020].

21 Manchester Local Care Organisation. Healthy schools (home page). Available: https://www.manchesterhealthyschools.nhs.uk/ [Accessed 9 May 2019].

22 Manchester Local Care Organisation. Healthy schools. Available: https://www.manchesterhealthyschools.nhs.uk/health-areas/healthylifestyles/resources [Accessed 9 May 2019]. 
23 Junghans $\mathrm{C}$, Feder G, Hemingway $\mathrm{H}$, et al. Recruiting patients to medical research: double blind randomised trial of "opt-in" versus "opt-out" strategies. BMJ 2005;331:940.

24 May CR, Johnson M, Finch T. Implementation, context and complexity. Implement Sci 2016;11:141.

25 May C. Towards a general theory of implementation. Implement Sci 2013;8:1-14.

26 Oakley A. Women and children first and last: parallels and differences between children's and women's studies. In: Mayall B, ed. Children's childhoods:observed and experienced. Falmer Press, 1994: 184. https://books.google.co.uk/books?hl=en\&lr=\&id=dTqQAgAAQBAJ\& oi=fnd\&pg=PA13\&dq=oakley+1994+research+children\&ots= epFguvpNx3\&sig=JDNtU6izOklleQh3dE8mPIfFqhl\#v=onepage\&q= oakley 1994 research children\&f=false

27 Braun V, Clarke V. Using thematic analysis in psychology. Qual Res Psychol 2006;3:77-101.

28 Peters S. Qualitative research methods in mental health. Evid Based Ment Health 2010;13:35-40.

29 Braun V, Clarke V. To saturate or not to saturate? Questioning data saturation as a useful concept for thematic analysis and sample-size rationales. Qual Res Sport Exerc Health 2019;2:1-16.

30 WHO. World Health Organisation: obesity and overweight, 2017. Available: http://www.who.int/mediacentre/factsheets/fs311/en/ [Accessed 29 Jul 2017].

31 Swinburn B, Kraak V, Rutter $\mathrm{H}$, et al. Strengthening of accountability systems to create healthy food environments and reduce global obesity. Lancet 2015;385:2534-45.

32 National Institute for Health and Care Excellence (NICE). Identifying the key elements and interactions of a whole system approach to obesity prevention. London, 2011. Available: https://www.nice. org.uk/guidance/ph42/evidence/review-1-identifying-the-keyelements-and-interactions-of-a-whole-system-approach-to-obesityprevention-pdf-69056029 [Accessed 16 Feb 2018].
33 Goldthorpe J, Epton T, Keyworth C, et al. Who is responsible for keeping children healthy? a qualitative exploration of the views of children aged 8-10 years old. BMJ Open 2019;9:e025245.

34 Clarke JL, Griffin TL, Lancashire ER, et al. Parent and child perceptions of school-based obesity prevention in England: a qualitative study. BMC Public Health 2015;15:1224.

35 Jalali MS, Sharafi-Avarzaman Z, Rahmandad H, et al. Social influence in childhood obesity interventions: a systematic review. Obes Rev 2016;17:820-32.

36 Evans CEL, Harper CE. A history and review of school meal standards in the UK. J Hum Nutr Diet 2009;22:89-99.

37 Evans CEL, Cleghorn CL, Greenwood DC, et al. A comparison of British school meals and packed lunches from 1990 to 2007: meta-analysis by lunch type. Br J Nutr 2010;104:474-87 http://www. journals.cambridge.org/abstract_S0007114510001601

38 Langford R, Bonell C, Jones $\mathrm{H}$, et al. Obesity prevention and the health promoting schools framework: essential components and barriers to success. Int J Behav Nutr Phys Act 2015;12:15.

39 Eustachio Colombo P, Patterson E, Elinder LS, et al. The importance of school lunches to the overall dietary intake of children in Sweden: a nationally representative study. Public Health Nutr 2020;23:1705-15.

40 Lobstein T, Jackson-Leach R, Moodie ML, et al. Obesity 4 child and adolescent obesity: part of a bigger picture. Ser 2510. Available: http://thelancet.com/pdfs/journals/lancet/PIIS0140-6736(14)61746-3. pdf [Accessed 29 Jul 2017].

41 Lewis CC, Fischer S, Weiner BJ, et al. Outcomes for implementation science: an enhanced systematic review of instruments using evidence-based rating criteria. Implement Sci 2015;10:155.

42 Carroll C, Patterson M, Wood S, et al. A conceptual framework for implementation fidelity. Implement Sci 2007;2:40.

43 Michie S, Richardson M, Johnston M, et al. The behavior change technique taxonomy (V1) of 93 hierarchically clustered techniques: building an international consensus for the reporting of behavior change interventions. Ann Behav Med 2013;46:81-95. 